\title{
Inosine Pranobex (Isoprinosine) - a Potential Adjuvant in the Management of Chronic HBV Infection
}

\author{
Zahariy Krastev, Nina Nikolova, Deian Jelev, Krasimir \\ Antonov, Lyudmila Mateva
}

University Hospital "St. Ivan Rilski" Sofia, Clinic of Gastroenterology

\begin{abstract}
After achieving a durable on-treatment virological response with NUC (nucleos(t)ide analogues), adding an immunomodulating agent seems to have beneficial effect on the course of chronic HBV disease. Methods: Nine patients were investigated $(5-\mathrm{HBeAg}(-)$ and $4-\mathrm{HBeAg}(+)$. All patients achieved durable on-treatment virological response with NA and then Isoprinosine was added for a period of 21 to 27 months. Serum HBsAg and HBV DNA levels were evaluated at a 3-month interval. Aim: The aim of the present study was to evaluate the effect of adjuvant immunomodulation with Isoprinosine in patients with chronic HBV infection who achieved durable suppression of HBV DNA on-treatment with NUC. Results: In HBeAg-negative patients an initial increase of qHBsAg was observed in $4 / 5$ of patients after the adding of Isoprinosine. On month 15 of combined therapy a reduction of more than $50 \%$ from the baseline $\mathrm{HBsAg}$ level was found in $4 / 5$ of patients $(\mathrm{P}=0.043)$. In $\mathrm{HBeAg}$-positive patients there was no significant reduction of $\mathrm{HBsAg}$ during the follow-up. A reduction of HBsAg levels (about 30\%) from the baseline was established in $3 / 4$ patients at month 18 . In the remaining one patient a reduction of $70 \%$ was established at month 27. There was an initial increase of $\mathrm{HBsAg}$ in $3 / 4$ patients. In $3 / 4$ of the patients there was a negativation of $\mathrm{HBeAg}$. Conclusion: After adding Isoprinosine to $\mathrm{NA}, \mathrm{HBeAg}$-loss was achieved in $3 / 4$ of $\mathrm{HBeAg}$ positive patients. HBsAg decline was more pronounced in $\mathrm{HBeAg}$-negative subjects, which was not observed in NUC monotherapy. Isoprinosine in combination with NUC is safe and well tolerated.
\end{abstract}

Key words: HBV, nucleos(t)ide analogues, Inosine pranobex, immunomodulation 


\section{Background}

The ideal treatment end point is loss of HBsAg in both HBeAg-positive and negative patients, but it is rarely achievable with available therapy (time limited interferon therapy (Peg-IFN) and long-term treatment with nucleos(t)ide analogues (NUC). Induction of durable HBeAg loss and seroconversion to anti-HBe (in about 18 to $30 \%$ of HBeAg-positive patients depending on therapy) and sustained off-therapy virological suppression of HBV DNA is a satisfactory end point, because it has been shown to be associated with improved prognosis (1).

The template of hepatitis B virus (HBV) transcription is the covalently closed circular DNA (cccDNA), which plays a key role in the life cycle of the virus and permits the persistence of infection. The persistence of cccDNA in the nucleus of infected hepatocytes, may explain HBV reactivation after discontinuation of anti-viral therapy $(2,3)$.

Moreover, the HBV genome integrates into the host genome and might favour oncogenesis and the development of HCC $(4,5)$.

Continued treatment with NA suppresses HBV DNA, but when it can be stopped is not yet forthcoming (6). After discontinuation of therapy often a rapid reactivation occurs with an increase of serum $\mathrm{HBeAg}$ and HBV DNA, clinical exacerbation of hepatitis, liver failure and even death (7). Krastev et al. showed three cases of attempts to prevent such reactivation after stopping lamivudine by using interferon or inosine pranobex (Isoprinosine) (8).

New drugs based on immunomodulation are being developed such as different therapeutic vaccines and TLR agonists (9). The results from add-on Peg-IFN or other immunomodulators to NUC are limited and controversial (10-15).

After achieving a durable on-treatment virological response with NA (undetectable serum HBV DNA levels), quantitative $\mathrm{HBsAg}$ (qHBsAg) is an important marker for the course of the disease (16). In these cases the adding of an immunomodulating agent seems to have beneficial effect on the course of chronic HBV disease. Such an immunomodulator is Isoprinosine. Our preliminary results with add-on Isopprinosin to NUC were promising both in $\mathrm{HBeAg}$-positive and $\mathrm{HBeAg}$-negative subjects $(17,18)$.

Inosine pranobex (Isoprinosine) is a purine analogue with immunomodulating and antiviral ability, including IFN-gamma production and enhanced T-cell immune response $(19,20)$. Various studies discuss its possible role in the treatment of chronic $\operatorname{HBV}$ infection $(8,21,22)$. Isoprinosine is used in protracted forms of acute hepatitis A and B, as well as CMV-induced hepatitis $(23,24)$. According to Krastev Z., one day Isoprinosine intake led to increase in lymphocyte count in healthy people (25).

There are no sufficient data for the use of immunomodulating agents in HBV therapy, especially adding it to NA.

\section{Aim}

The aim of the present study was to evaluate the effect of adjuvant immunomodulation with Isoprinosine in patients with chronic HBV infection who achieved durable suppression of HBV DNA on-treatment with NUC, but who were still HBeAg-positive and/or with steady serum HBsAg levels during NUC monotherapy 


\section{Methods}

\section{Patients and Treatment}

Nine patients were investigated (5 pts HBeAg-negative - males (4-CHB and 1 with Child-A liver cirrhosis) and 4 pts $\mathrm{HBeAg}$-positive (all with $\mathrm{CHB}$, one female). Eight patients were treated long-term with tenofovir and 1-with lamivudine (the patient with liver cirrhosis) (Table 1.). HCV, HDV and HIV co-infections were excluded prior to therapy. All patients achieved durable on-treatment virological response and then inosine pranobex in a dose of $3 \mathrm{~g}$ p.o. daily (5 days weekly) was added to NA for 21 to 27 months. Serum HBsAg and HBV DNA levels were evaluated on a 3-month interval.

Table1. Baseline characteristics of the studied patients (before adding Isoprinosine)

\begin{tabular}{|c|c|c|c|}
\hline & All patients & HBe-positive & HBe-negative \\
\hline Number of pts & 9 & 4 & 5 \\
\hline Age - median, range & $37(26-56)$ & $32(26-40)$ & $51(37-56)$ \\
\hline Male /female (n) & $8 / 1$ & $3 / 1$ & $5 / 0$ \\
\hline HBsAg IU/ml - median, range & 4130 & 10324 & 4130 \\
& $(291-21870)$ & $(2551-21870)$ & $(291-11564)$ \\
\hline Chronic hepatitis /F 0-3 Metavir/ & 7 & 3 & 4 \\
\hline Liver cirrhosis & 2 & 1 & 1 \\
\hline
\end{tabular}

\section{Methods}

H sAg quantification - HBsAg levels were measured by the fully automated Roche® diagnostic test and the results were expressed as $\mathrm{IU} / \mathrm{ml}$. This is an electrochemiluminescence immunoassay.

HBV-DNA measurement. HBV DNA quantitation was done on patient's serum $\left(\begin{array}{lll}500 & \text { I) using LightCycler }\end{array}\right.$ real time PCR assay (Roche Diagnostics). Results were expressed as IU $/ \mathrm{ml}$.

Hepatitis B e antigen (HBeAg) and antibody against $\mathrm{HBeAg}$ (anti-HBe) status was determined using enzyme immunoassays.

Standard laboratory methods were used for the assessment of blood chemistry parameters. The values of $A L T<40 \mathrm{U} / \mathrm{ml}$ were accepted for normal according to the laboratory report.

Liver biopsies. Pre-treatment liver biopsy applying Menghini's method was performed in 7 patients and evaluated by using METAVIR system. Two patients without biopsy were with proved liver cirrhosis (F4).

Statistical methods. Standard statistical analyses were performed using SPSS® v. 17.0. Individual characteristics between groups were evaluated by means of the Wilcoxon and Mann-Whitney. All reported $P$ values are two-sided, and $P$ values less than 0,05 were considered significant.

Written informed consent was obtained from each participating patient.

\section{Results}

Fifteen months after adding Isoprinosine to NUC we observed a significant reduction of HBsAg levels $(P=0.012)$. 


\section{HBeAg - negative patients}

Initial increase of qHBsAg was observed in $4 / 5$ of patients after the adding of inosine pranobex (3, 6 or 9 months). On the $15^{\text {th }}$ month of combined therapy a reduction of more than $50 \%$ from the baseline $\mathrm{HBsAg}$ level was found in $4 / 5$ of patients $(P=0.043)$. All patients remained aviremic with normal ALT during therapy. There was also a statistical difference between basal $\mathrm{HBsAg}$ levels and those at month 21 ( $P=0.043$, Wilcoxon) (Fig.1 A and B).

Fig. 1 A. HBsAg levels during Isoprinosine intake in HBeAg-negative patients with durable ontreatment virologic response (nucleos(t)ide analogues) (HBVDNA - negative). (patients 1 and 2)

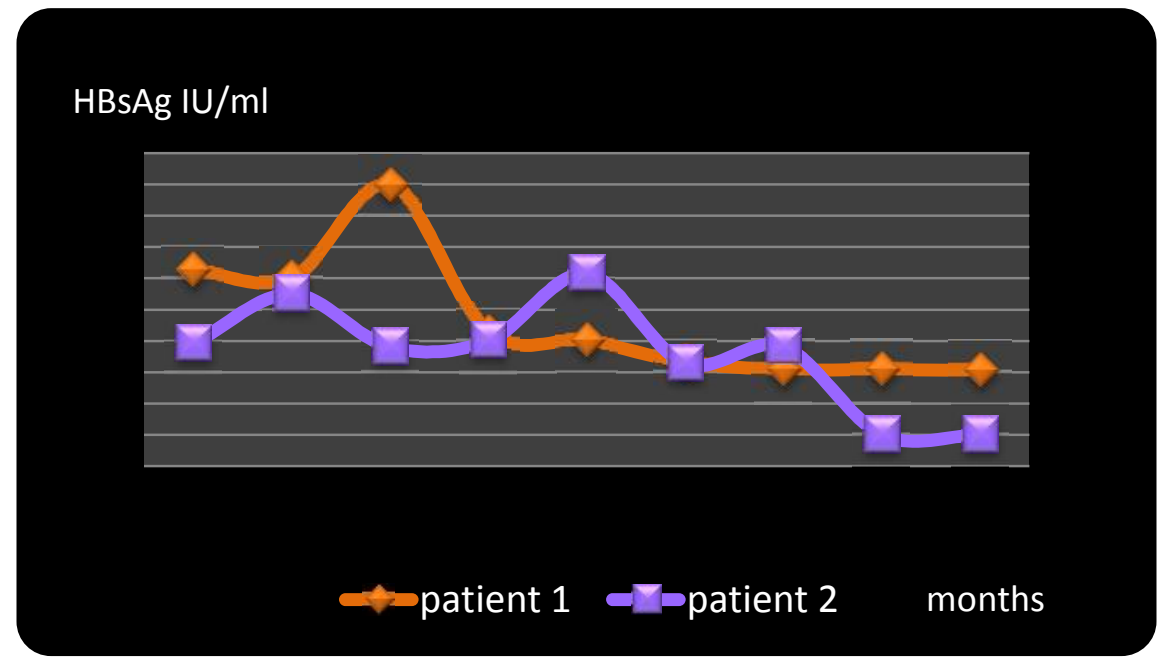

Fig. $1 \mathrm{~B}$. HBsAg levels during Isoprinosine intake in HBeAg-negative patients with durable ontreatment virologic response (nucleos(t)ide analogues) (HBV DNA - negative). (patients 3, 4 and 5).

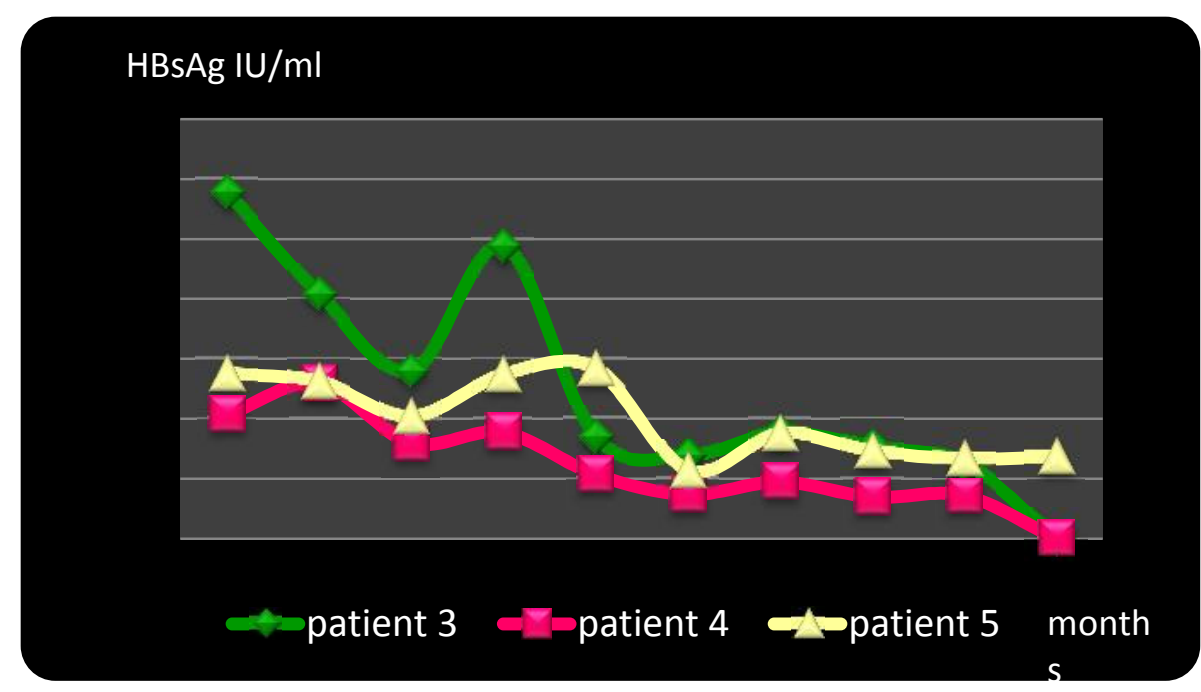




\section{Case presentation of two $\mathrm{HBeAg}$-negative patients (from the observed group)}

\section{$\underline{1^{\text {st }} \text { case: }}$}

The studied patient was a 56 years old man with a known HBV-infection for $>20$ years. Child- cirrhosis was proved 10-year ago. He was $\mathrm{HBeAg}(-) / a n t i-\mathrm{HBe}(+)$, without HCV, HDV and HIV co-infections. Lamivudine was started due to high viral load, jaundice, and elevated aminotransferases. After the first treatment year, HBV DNA was persistently undetectable. Two years post initiation of lamivudin, Peg-IFN$\alpha 2 \mathrm{a}$ was added (becuase of the low HBsAg levels $-135 \mathrm{IU} / \mathrm{ml}$ ) for 6 months and a gradual rise of $\mathrm{HBsAg}$ (from 135 to $5600 \mathrm{IU} / \mathrm{ml}$ ) and ALT $(115 \mathrm{U} / \mathrm{ml}$ ) was observed. Peg-IFN- $\alpha 2 a$ was discontinued and two months later the patient was with normal aminotransferases and decreased HBsAg. After 9 months another immunomodulator (Isoprinosine) was added. Six months later HBsAg rose again, but only up to $700 \mathrm{IU} / \mathrm{ml}$ and without ALT-elevation. Combined treatment was continued and HBsAg level progressively decreased to 206 at month 27. Therapy was well tolerated and no side effects were observed (Fig.2).

Fig. 2. Long-term monitoring during different treatment regimens (Lamivudine - Peg-IFN-alfa 2a and Lamivudine - Isoprinosine)

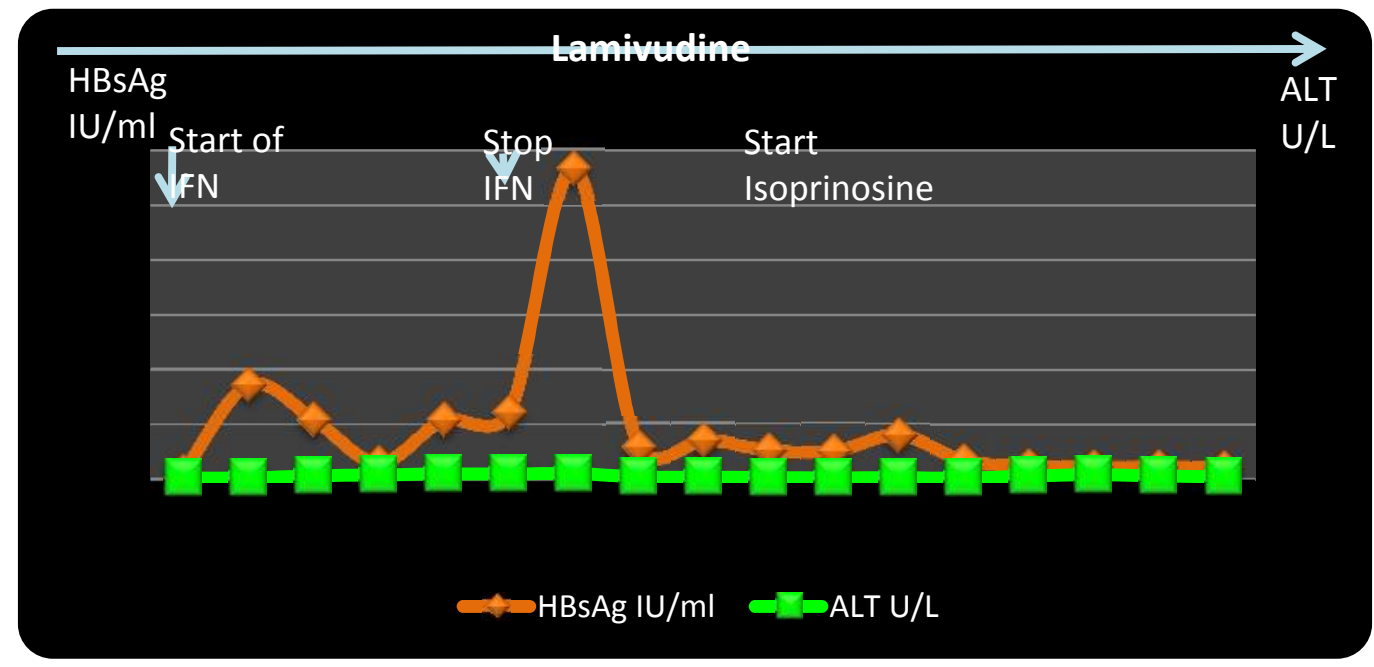

\section{$\underline{2^{\text {nd }} \text { case: }}$}

A 37 years old male with anti-HBe(+) chronic hepatitis B (METAVIR A2; F2) started tenofovir treatment. $\mathrm{He}$ was non-responder to previous Peg IFN $\alpha 2 a$ therapy and was negative for anti-HCV, anti-HDV and anti-HIV. At treatment month12 HBV DNA was undetectable and HBsAg levels were $13000 \mathrm{IU} / \mathrm{ml}$, and at month18 HBsAg levels were $10300 \mathrm{lU} / \mathrm{ml}$. Then (at month 18) Isoprinosine was added to tenofovir. Three months later $\mathrm{HBsAg}$ level was $9700 \mathrm{IU} / \mathrm{ml}$ and isoprinosine was discontinued. An elevation (rebound) of HBsAg level to $11546 \mathrm{IU} / \mathrm{ml}$ was observed after 3 months without isoprinosine, but subject remained aviremic on tenofovir monotherapy. Isoprinosine was re-started and this led to repeating decrease of $\mathrm{HBsAg}$ level to $9030 \mathrm{IU} / \mathrm{ml}$. Treatment with both drugs was continued and HBsAg level progressively decreased to $5564 \mathrm{IU} / \mathrm{ml}$ at month 6, 3381 (month 12) and 2513 (month 24) post second initiation of Isoprinosine (patient 3 from Figure 1 B, Figure 3). 
Fig. 3. HBsAg levels during Isoprinosine intake in patient (№3, $2^{\text {nd }}$ case) with rebound of $\mathrm{HBs} \mathrm{Ag}$ after its discontinuation and a progressive reduction after a second initiation

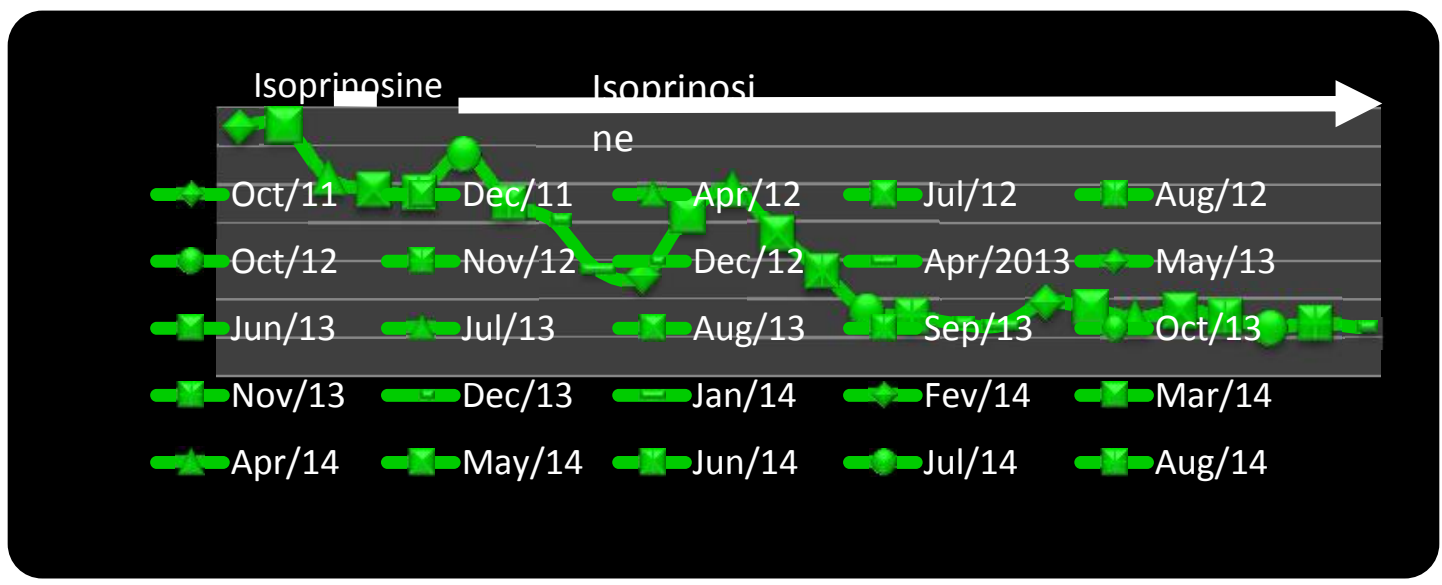

\section{$\underline{\text { HBeAg-positive patients }}$}

In $\mathrm{HBeAg}$-positive patients there was no significant reduction of $\mathrm{HBsAg}$ from the baseline to month 15 to $21(\mathrm{P}>0.05)$. A reduction of $\mathrm{HBsAg}$ levels (about $30 \%$ from the baseline) was established in $3 / 4$ patients at month 18. In the remaining one patient a reduction of $70 \%$ was established at month 27 . There was an initial increase of $\mathrm{HBsAg}$ (months 3 to 6 ) in 3/4 patients (Fig.4 A and B).

Fig. 4 A. HBsAg levels during Isoprinosine intake in HBeAg-positive patients with durable ontreatment virological response (nucleos(t)ide analogues) (HBVDNA - negative). (patients 1 and 2)

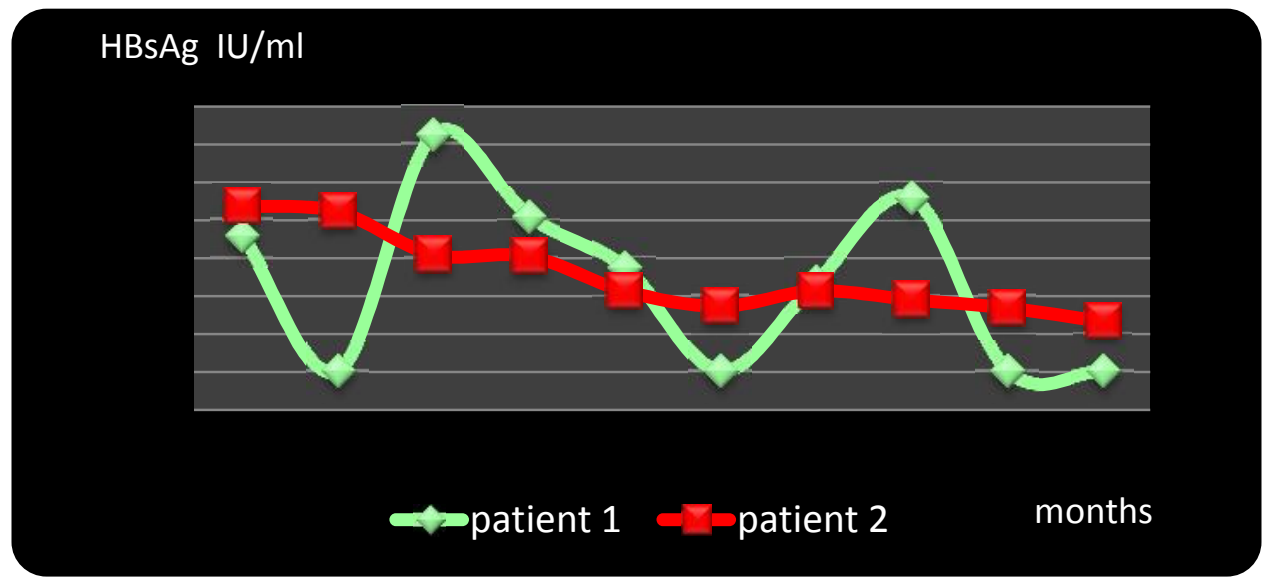


Fig. 4 B. HBsAg levels during Isoprinosine intake in $\mathrm{HBeAg-positive} \mathrm{patients} \mathrm{with} \mathrm{durable} \mathrm{on-}$ treatment virological response (nucleos(t)ide analogues) (HBVDNA - negative), (patients 3 and 4)

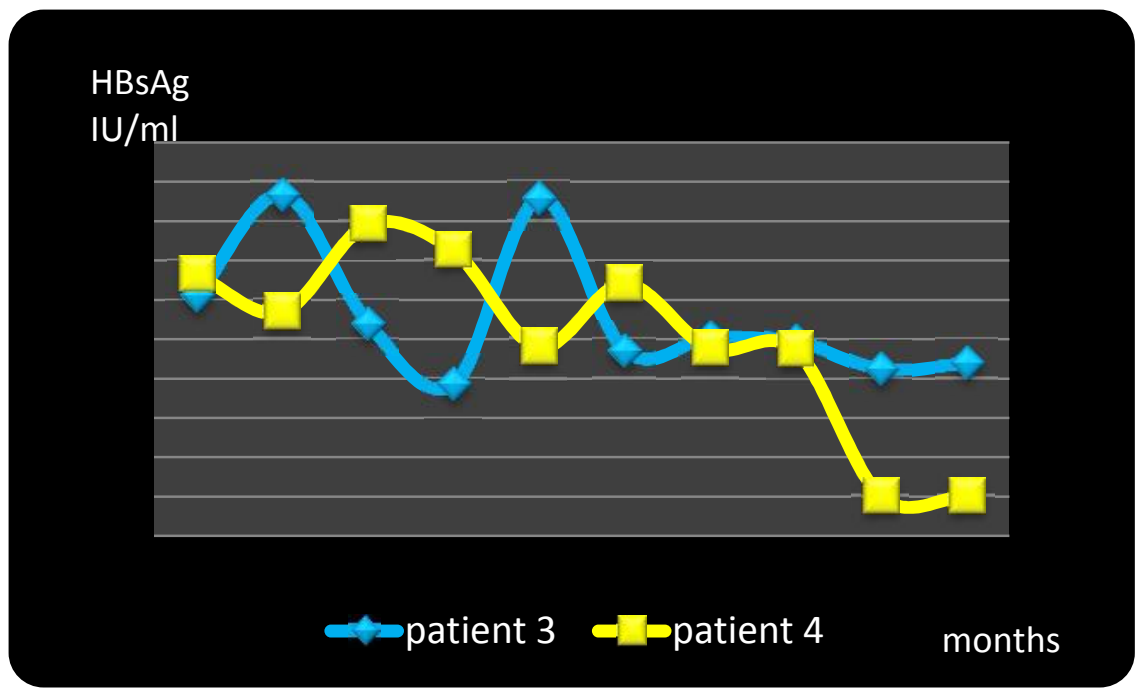

Three out of four HBeAg-positive patients became HBeAg-negative during combined therapy immunomodulator (Isoprinosine) and NUC (Table 2.).

Table 2. Characteristics of patients who lost $\mathrm{HBeAg}$

\begin{tabular}{|c|c|c|c|c|}
\hline Age & Gender & Stage of fibrosis & NUC & $\begin{array}{c}\text { HBeAg-negativation } \\
\text { (period of combined regime) }\end{array}$ \\
\hline 40 & Male & F4 (Cirrhosis) & Tenofovir & $15^{\text {th }}$ month \\
\hline 35 & Male & 3 & Tenofovir & $6^{\text {th }}$ week \\
\hline 29 & Male & 1 & Tenofovir & $3^{\text {rd }}$ month \\
\hline
\end{tabular}

In the $1^{\text {st }}$ patient (40 years old male, with cirrhosis) - this negativation was achieved at the 15 th month, but he remained antiHBeAg-negative (patient 3 from figure 3-B).

The $2^{\text {nd }}$ patient (35 years old male, METAVIR A3; F3, patient 2 from figure $3-A$ ), six weeks after the adding of Isoprinosine, lost $\mathrm{HBeAg}$ without seroconversion. Nine months after Isoprinosine initiation he remained $\mathrm{HBeAg}(-)$. On the $12^{\text {th }}$ month of combined therapy anti-HBeAg-antibodies appeared. HBsAg level dropped from $21870 \mathrm{IU} / \mathrm{ml}$ to $10689 \mathrm{IU} / \mathrm{ml}\left(12^{\text {th }}\right.$ month). After that the patient was HBeAg-negative and antiHBe-negative. Presently (27 $7^{\text {th }}$ month) the patient is in the same HBeAg status, and HBsAg dropped to $6646 \mathrm{IU} / \mathrm{ml}$.

The $3^{\text {rd }}$ patient who lost $\mathrm{HBeAg}$ is a 29 years old male $(\mathrm{F} 1)$ receiving a tenofovir monotherapy $(300 \mathrm{mg} / \mathrm{d})$ for 8 years, but remained $\mathrm{HBeAg}$ positive (this is patient 4 from figure $3-\mathrm{B}$ ). Isoprinosine was added to tenofovir. Three months later the patient became $\mathrm{HBeAg}(-) / a n t i-\mathrm{HBe}(-)$. Fifteen months after the adding of Isoprinosine he remained $\mathrm{HBeAg}$-negative. The levels of $\mathrm{HBsAg}$ were without significant changes. 
Isoprinosine was well tolerated and no side effects were observed during combination with NUC both in $\mathrm{HBeAg}$-negative and in HBeAg-positive patients. A mild elevation of serum uric acid level was observed in one patient, but was not associated with any clinical symptoms.

\section{Discussion}

A problem inherent to all current HBV therapies is their inability to achieve a curative outcome. HBsAg clearance and development of anti-HBs occurs in only a minority of cases not exceeding $8 \%$ after both Peg-IFN and NUC therapy $(1,9)$. Durable HBV DNA suppression with NUC is only possible with continued treatment for many years. It leads to functional and morphological improvement of liver disease, but the effect is lasting only during NUC therapy. Usually, HBV reactivation rapidly occurs after treatment discontinuation (26).

The persistence of cccDNA in the nucleus of infected hepatocytes is the reason for the failure of HBV eradication. NUC are potent inhibitors of HBV replication, but they have only a weak effect on cccDNA, which is not enough to eradicate it (27). Theoretically, the latter is achievable through both inhibiting the formation of cccDNA and enhancing the clearance of infected hepatocytes by immune-mediated mechanisms. These facts strongly suggest that the combination of direct acting antivirals with immunomodulators is a reasonable future treatment approach (9).

We therefore decided to add a drug with proven immunomodulatory properties to ongoing NUC therapy in subjects who already achieved sustained viral suppression on NUC monotherapy, but remained HBeAgpositive and/or with steady HBsAg levels. For the discussed purpose Isoprinosine is an appropriate agent due to its immudulatory action. We recently showed that Isoprinosine can induce rapid immune response in healthy adults within 9 hours after single-day intake (25). It enhanced T-cell immune response by increasing T lymphocyte proliferation and NK cell activity (28). In addition Isoprinosine enhanced IL-2 production, upregulating the expression of IL-2 receptor in vitro (19). It also significantly increased the IFNgamma secretion and decreased the IL-4 production (19). Treatment (of human PBMC) with Isoprinosine enhanced IL-2 production by PBMC from 7 of 10 normal individuals (29). Our previous study on healthy volunteers also showed that Isoprinosine treatment leads to increase in serum levels of IFN- $\gamma$, IL-2, IL-10, and TNF- $\alpha$ at 7 th to 10 th day (20)

Even though the number of patients was limited, the present study demonstrates for the first time the beneficial effect of Isoprinosine in patients with durable viral suppression on NUC therapy. We observed a significant decline in HBsAg levels in 15 to 27 months after initiation of Isoprinosine, which was more pronounced in $\mathrm{HBeAg}$-negative subjects in whom HBsAg levels have not decreased during NA monotherapy. Furthermore, $3 / 4$ of $\mathrm{HBeAg}$-positive patients lost $\mathrm{HBeAg}$ without seroconversion.

Previous studies evaluating the HBsAg kinetics in both $\mathrm{HBeAg}$-negative and $\mathrm{HBeAg}$-patients clearly demonstrated that HBsAg level remains steady even after successful viral suppression with NUC for many years (30-32) In HBeAg-positive CHB a rapid HBsAg decline was described only in a minority of patients who are with high baseline ALT and HBsAg level. It occurs within the first 6 months of NUC therapy. In cases without subsequent $\mathrm{HBsAg}$ clearance, HBsAg titer remains relatively stable after the first year of NUC therapy or decreases very slowly, so HBsAg loss rarely occurs (30-32). Mathematical models showed that the majority of patients will need more than 3 or 4 decades of NUC therapy for HBsAg seroclearance (31).

We believe that the described reduction of qHBsAg in our study is strongly related to adjuvant immunomodulation. HBsAg levels were relatively stable 6 months prior to initiation of Isoprinosine. The effect of immunomodulation is very demonstrative in subject \#3 (figure 1-B and figure 3). In this patient Isoprinosine led to initial HBsAg decline. Interruption of immunomodulation was associated with elevation of qHBsAg, which again dropped down after reintroduction of Isoprinosine therapy. 
Interestingly, in $7 / 9$ of patients an initial elevation of HBsAg level was found, which occurred 3 to -9 months after the adding of Isoprinosine. Prolongation of Isoprinosine led to further HBsAg decline and reaching levels lower than baseline. Recent studies with add-on Peg-IFN to NUC also described similar initial elevation of HBsAg level in some subjects $(11,14)$. Moreover, in the present study we observed quite a similar pattern of HBsAg kinetics after consecutive adding of two different immunomodulators: Peg-IFN and Isoprinosine (figure. 2). Together all these data clearly show that the adding of immunomodulators to NUC may cause a transient elevation of $\mathrm{qHBsAg}$ and ALT, but prolongation of therapy is associated with further HBsAg decline and may improve the course of chronic liver disease. It seems that Peg-IFN induces more sever ALT elevation than Isoprinosine (figure 2). We recently found such an elevation of qHBsAg 3 months post initiation of NUC monotherapy in $1 / 4$ of patients with further $\mathrm{HBsAg}$ decline in HBeAg-positive subjects - data in press (33). The reason for the reported early elevation of $\mathrm{qHBsAg}$ remains unclear. One can speculate that this may be due to release of HBsAg after enhanced clearance of infected hepatocytes as a result of restoration of host immune response against HBV. However, we did not observe always parallel elevation of ALT levels, so further studies are needed to elucidate this phenomenon.

The role of host immune response for HBsAg clearance was recently reported by J. Jaroszewicz et al. (34) who showed that high baseline interferon-inducible protein-10 (IP-10) levels as well as elevation of baseline ALT $>5 x$ predicts HBsAg-loss during NUC therapy. As HBsAg seroclearance remains a rare event with NA, the adding of immunomodulators to NUC is an essential therapeutic strategy to increase this important event. Current data with add-on of Peg-IFN are contradictory. Early studies were not successful enough, but in all of them the added Peg-IFN was given in a short course of 24 weeks $(10,11)$. On the other hand, extension of added Peg-IFN for up to 96 weeks in accordance with changes in HBsAg titers in a small series of $\mathrm{HBeAg}$-negative subjects was associated with HBsAg-loss in 6 out of 10 patients (14). This treatment approach is currently under investigation and the interim data of a larger study with a similar design are also promising, but the trial is still ongoing (15). In the present study we also used longterm course of Isoprinosine added to NUC for 15 to 27 months. It seems that better treatment results could be achieved with prolongation of combined therapy. This hypothesis is based on recent suggestion that sustained inhibition of viral replication could facilitate the effect of Peg-IFN and other immunomodulators (14). Several novel immune modulatory agents, like different therapeutic vaccines or toll-like-receptor agonists, are currently in clinical development (9). The design of future clinical trials should be focused on elucidating the optimal duration of these new drugs in combination with direct antiviral agents.

It is unclear whether the immunotherapy should be added after achieving the undetectable serum HBV DNA on NA therapy or the two drugs should be started together. A recent trial reported a higher rate of HBsAg-loss after combined treatment with Peg IFN plus tenofovir vs. Peg IFN monotherapy (35). In contrast early trials with less potent NUCs (lamivudine and adefovir) failed to demonstrate any advantage of combined treatment versus Peg IFN alone $(36,37)$.

Measurement of HBsAg during NUC after achievement of persistently undetectable serum HBV DNA and normal ALT may provide essential additional information for the course of chronic liver disease. However, from a diagnostic perspective, it is important that $\mathrm{HBsAg}$ quantification detects all three forms of circulating HBsAg: mature HBV virions as well as two types of non-infectious subviral particles - spherical and filamentous forms. Both spherical and filamentous forms of HBsAg are secreted at levels far in excess of mature virions. HBsAg may also be produced from HBV DNA integrated into the host genome (38). Current assays target epitopes in the $S$ protein, and are therefore not capable of distinguishing between the different HBsAg proteins, nor can they distinguish between virion-associated HBsAg, subviral particles and HBsAg produced from integrated sequence (38). With regard to this new surrogate markers are needed that reflect better the interaction between cccDNA in the liver and host immune response against 
HBV. This could help to improve current knowledge on HBV basic science and thus to develop more successful and curable treatment strategies of chronic HBV infection.

\section{Conclusion}

This is the first report of successful decrease of qHBsAg in patients treated with NA by using an immunomodulator distinct from IFN. HBeAg-loss was achieved in $3 / 4$ of $\mathrm{HBeAg}$ positive patients. $\mathrm{HBsAg}$ decline was more pronounced in HBeAg-negative subjects, which was not observed in NUC monotherapy. Isoprinosine in combination with NUC is safe and well tolerated. The reduction of cccDNA in infected hepatocytes is achievable only through immune-mediated mechanisms and the combined treatment with NUC and Isoprinosine can be a helpful therapeutic approach. This treatment is safe and well tolerated. Further studies are needed to define more accurately the efficacy and safety profile of this combination

\section{References}

1. European Association for the Study of the Liver. EASL clinical practice guidelines: management of chronic hepatitis B virus infection. J Hepatol 2012;57:167-185.

2. Brechot $C$, Thiers $V$, Kremsdorf $D$, et al. Persistent hepatitis $B$ virus infection in subjects without hepatitis B surface antigen: clinically significant or purely "occult"? Hepatology 2001;34:194-203.

3. Moucari R, Martinot-Peignoux M, Mackiewicz V, et al. Influence of genotype on hepatitis B surface antigen kinetics in hepatitis $B$ e antigen-negative patients treated with pegylated interferonalpha2a. Antivir Ther 2009;14:1183-1188.

4. Bonilla GR, Roberts LR. The role of hepatitis $B$ virus integrations in the pathogenesis of human hepatocellular carcinoma. J Hepatol 2005;42:760-777.

5. Moucari R, Mackiewicz V, Lada O, et al. Early serum HBsAg drop: a strong predictor of SVR to Pegilated-IFN alfa 2a in HBeAg-negative patients. Hepatology 2009;49:1151-1157.

6. Marcellin $\mathrm{P}$, Buti M, Krastev Z, et al. Kinetics of hepatitis $B$ surface antigen loss in patients with HBeAg-positive chronic hepatitis B treated with tenofovir disoproxil fumarate. J Hepatol 2014;61: 1228-1237.

7. Tseng TC, Liu CJ, Yang HC, et al. Determinants of spontaneous surface antigen loss in hepatitis B e antigen-negative patients with a low viral load. Hepatology 2012;55:68-76.

8. Krastev Z, Antonov K, Jelev D. The prevention of an expected hepatic flare in HBe negative patients after lamivudine discontinuation. J Gastrointestin Liver Dis 2006;15:389-391.

9. Baltayiannis G, Karayiannis P. Treatment Options Beyond IFN $\alpha$ and NUCs for Chronic HBV Infection. J Viral Hepat 2014;21:753-761.

10. Kittner JM, Sprinzl MF, Grambihler A, et al. Adding pegylated interferon to a current nucleos(t)ide therapy leads to HBsAg seroconversion in a subgroup of patients with chronic hepatitis $\mathrm{B}$. J Clin Virol 2012;54:93-95.

11. Lampertico $P$, Invernizzi F, Facchetti F, et al. Add-on PEG-IFN improves HBsAg kinetics in patients long-term fully suppressed by nucleos(t)ide analogues. J Hepatol 2012;56:2:s207.

12. Barone $\mathrm{M}$, lannone $\mathrm{A}$, Di Leo A. HBsAg clearance by Peg-interferon addition to a long-term nucleos(t)ide analogue therapy. World J Gastroenterol 2014;20:8722-8722.

13. Sonneveld $\mathrm{MJ}$, Xie $\mathrm{Q}$, Zhang $\mathrm{N}$, et al. Adding peginterferon alpha-2a to entecavir increases $\mathrm{HBsAg}$ decline and $\mathrm{HBeAg}$ clearance-first results from a global randomized trial(ARES Study). Hepatology 2012;56:1:199A. 
14. Ouzan D, Pénaranda G, Joly $H$, et al. Add-on peg-interferon leads to loss of HBsAg in patients with HBeAg-negative chronic hepatitis and HBV DNA fully suppressed by long-term nucleotide analogues. J Clin Virol 2013;58:4:713-717.

15. Lampertico $\mathrm{P}$, Colombo M, Brunetto MR, et al. Add-on Peginterferon Alfa-2a significantly reduces HBsAg levels in chronic hepatitis B, HBeAg-negative, genotype D patients fully suppressed on nucleot(s)ide analogues treatment: HERMES Study Interim Analysis. Late-Breaking Poster presented at AASLD November, 2014, Bostan, USA.

16. Andersson KL, Chung RT. Monitoring during and after antiviral therapy for hepatitis B. Hepatology 2009;49:5:S166-173.

17. Nikolova N, Jelev D, Antonov K, et al. HBsAg level after consecutive add-on peginterferon-alfa 2a and inosine pranobex in long-term responder to lamivudine, European Gastro Update eposter, Vienna, May 2014.

18. Nikolova N, Jelev D, Antonov K, et al. Inosine pranobex can enhance HBeAg-loss during longterm tenofovir treatment. EASL Monothematic Conference: Translational Research in Chronic Viral Hepatitis - Bridging Basic Science and Clinical Research, Lyon, France 2013; Abstract Book: p. 171.

19. Milano S, Dieli M, Millott S, et al. Effect of isoprinosine on IL-2, IFN-gamma and IL-4 production in vivo and in vitro. Int J Immunopharmacol 1991;13:1013-1018.

20. Petrova $M$, Jelev D, Ivanova $A$, et al. Isoprinosine affects serum cytokine levels in healthy adults. J Interferon Cytokine Res 2010;30:223-228.

21. Cianciara J, Laskus T, Gabinska E, et al. Isoprinosine in the treatment of chronic active hepatitis B. Scand J Infect Dis 1990;22:645-648.

22. De Luca D, Russo V, Caporale G, et al. A. Study of the cellmediated immunity in asymptomatic carriers of viral hepatitis (HBsAg) surface antigens and hypothesis on the elimination of these antigens with isoprinosine. Arch Med Genral 1980;32:635-640.

23. Kasimov IZ. Efficiency of isoprinosine in the complex treatment of acute virus hepatitis $B$ (Russian). Lik Sprava 2004;7:74-77.

24. Nicoara , Crisan A. Possibilities to modulate the immune response during infections. TMJ 2003; 53:3-4.

25. Krastev Z, Jelev D, Ivanova R. Isoprinosine induces a rapid lympho-mononuclear response in adult probants. 2014 in press.

26. Petersen J, Buggish $P$, Stoehr A, et al. Stopping long term nucleo(t)ide analogue therapy before HBsAg loss in HBe negative CHB patients: experience of five referral centers in Germany. J Hepatol 2012;54:1:s299-300.

27. Tseng TC, Kao JH. Clinical utility of quantitative HBsAg in natural history and nucleos(t)ide analogue treatment of chronic hepatitis B: new trick of old dog. J Gastroenterol 2013; 48:1: 13-21.

28. Barasoain I, Rejas MT, Ojeda G, et al. In vivo effect of isoprinosine on interleukin-2 production, lymphocyte mitogenesis and NK activity in normal and cyclophosphamide immunosuppressed mice. Int J Immunopharmacol 1986;8:509-515.

29. Tsang KY, Boutin B, Pathak SK, et al. Effect of isoprinosine on sialylation of interleukin-2. Immunol Lett 1986;12:195-200.

30. Heathcote EJ, Marcellin P, Buti M. et al. Three-year efficacy and safety of tenofovir disoproxil fumarate treatment for chronic hepatitis B. Gastroenterology 2011;140:132-143.

31. Zoutendijk R, Hansen BE, van Vuuren AJ, et al. Serum HBsAg decline during long-term potent nucleos(t)ide analogue therapy for chronic hepatitis $B$ and prediction of $\mathrm{HBsAg}$ loss. $J$ Infect Dis $2011 ; 204: 415-418$.

32. Fung J, Lai CL, Young J, et al. Quantitative hepatitis B surface antigen levels in patients with chronic hepatitis B after 2 years of entecavir treatment. Am J Gastroenterol. 2011;106:1766-1773. 
33. Nikolova N, Jelev D, Antonov D, et al. The decrease of HBsAg during nucleos(t)ide analogues therapy in Bulgarian patients 2014 in press.

34. Jaroszewicz J, Ho H, Markova A. et al. Hepatitis surface antigen (HBsAg) decrease and serum interferon-inducible protein-10 levels as predictive markers for HBsAg loss during treatment with nucleoside/nucleotide analogues. Antivir Ther 2011;16:915-924.

35. Marcellin P, Ahn S, Ma X. HBsAg Loss with Tenofovir Disoproxil Fumarate (TDF) plus Peginterferon alfa-2a (PEG) in Chronic Hepatitis B (CHB): Results of a Global Randomized Controlled Trial. Oral presentation at AASLD November, 2014, Bostan, USA. ABSTRACT FINAL ID:193.

36. Lau GK, Piratvisuth T, Luo KX, et al. Peginterferon Alfa-2a, lamivudine, and the combination for HBeAg-positive chronic hepatitis B. N Engl J Med 2005;352:2682-2695.

37. Marcellin P, Lau GK, Bonino F, et al., Peginterferon Alfa 2a HBeAg-negative chronic hepatitis B study group. Peginterferon alfa-2a alone, Lamivudin alone, and the two in combination in patients with HBeAg- negative chronic hepatitis B. N Engl J Med 2004;351:1206-1217.

38. Chan HL, Thompson A, Martinot-Peignoux M. et al. Hepatitis B surface antigen quantification: why and how to use it in 2011 - a core group report. $J$ Hepatol 2011;55:1121-1131.

\section{Corresponding author}

Zahariy Alexandrov Krastev

Clinic of Gastroenterology, University Hospital "St. Ivan Rilsky"

15 Acad. Ivan Geshov Blvd.

1431 Sofia, Bulgaria

Phone: +359 29526319

Fax: +359 28510615

e-mail: zahkrastev@gmail.com 